\title{
People and Nature: Toward an Ecological Model of Health Promotion
}

\author{
DANIEL L. DUSTIN \\ KELLY S. BRICKER \\ KERI A. SCHWAB \\ Department of Parks, Recreation, and Tourism \\ University of Utah \\ Salt Lake City, UT, USA
}

\begin{abstract}
Striving for a healthier relationship among individuals, families, communities, nations, and the environment is imperative at a time in history when humankind can change the face of the earth in monumental ways. This dynamic health relationship, with an emphasis on the contributions of parks, recreation, and tourism to health promotion, is the subject of this article. A broader conception of health that moves beyond human physical and mental health to include familial, communal, national, international, and global ecological health is called for, and a more comprehensive ecological model of health promotion, including consideration of health from a holistic ecological perspective, is presented. New directions for leisure research based on an ecological orientation to health promotion conclude the article.
\end{abstract}

Keywords biodiversity, ecological model of health promotion, restorative environments, sustainability, urbanization

In Last Child in the Woods: Saving Our Children from Nature-Deficit Disorder, journalist Richard Louv (2005) pieces together a jigsaw puzzle's worth of scientific evidence to support his claim that humankind is losing touch with its biological moorings in ways that are detrimental to human health, especially the health of children. The United States is $85 \%$ urbanized, and people have largely abandoned the country to make their living and homes in the city. Urban living is a manifestation of advancing technology, which makes it possible to work in more sedentary ways, stay inside more, and exercise less. The impact on health is disastrous. Obesity and obesity-related diseases such as high blood pressure, diabetes, congestive heart failure, strokes, and other maladies accompanying an urban sedentary lifestyle are all on the rise (U.S. Department of Health and Human Services, 2008).

Louv (2005) is especially concerned about the negative effects of urbanization on children. For a variety of reasons, children are also more sedentary, stay inside more, and exercise less (Clements, 2004; Kellert, 2005). From 2006 to 2007, participation in outdoor activities dropped $11.6 \%$ among U.S. children ages 6-17, and the trend continues (Outdoor 
Industry Foundation, 2008). Children spend inordinate amounts of time watching television, playing video games, sitting at their computers, and attending movies (Pergams \& Zaradic, 2006). Pergams and Zaradic have even coined a new term, videophilia, to describe this growing human inclination to be preoccupied with sedentary activities involving electronic media.

The increasing divide between people and nature jeopardizes human physical and mental health in significant ways (Turner, Nakamura, \& Dinetti, 2004). Research has shown, for example, that exposure to nature through early life experiences is integral to children's physical, emotional, and cognitive development (Faber Taylor \& Kuo, 2006; Faber Taylor, Kuo, \& Sullivan, 2002; Kellert, 2005). Playing outside is good for children. As adults, these same childhood experiences serve as a foundation for environmental advocacy (Chawla, 1988, 1998). To the extent that today's children play outdoors less, their personal growth and development are hampered, as is the likelihood that they will be environmental advocates upon reaching adulthood. Left unchecked, future citizens may end up detached from their fundamental ground of being and lose sight of their dependence on nature for its life-giving sustenance. Such ecological ignorance would then pose an even greater threat to human and environmental health.

Louv's (2005) prescription for what ails children is a heavy dose of nature. His remedy is based on the health benefits of active living and the health-restoring properties of natural environments. His thinking is rooted in the work of environmental psychologists who reason that humankind has spent most of its evolutionary history in close contact with the natural world (Kaplan \& Kaplan, 1989) in ways that have nurtured a deep affinity for it (Wilson, 1993). From this perspective, migration to the city has happened in the blink of an evolutionary eye, and people are now out of sorts with their own biology.

\section{The Urban Condition}

Thinking of contemporary human beings as products of a long history that began in the African savanna is a theme that has been developed in the environmental psychology literature (Altman \& Wohlwill, 1983; Kaplan \& Kaplan, 1989; Kellert, 2005; Proshansky, Ittelson, \& Rivlin, 1970). Having spent most of the past in close proximity to nature, environmental psychologists suggest humans may be "wired" for a world they no longer inhabit. Closeness to, and fondness for, nature has been cut off by the relatively recent arrival in the city. Detached from their biological moorings, people are now fundamentally out of step with their own nature, resulting in numerous health problems associated with the urban condition.

This separation between people and nature is reflected in many aspects of city life. People reside in built environments that do not lend themselves to physical activity or outdoor recreation. In most cases, transportation corridors are designed for motorized vehicles rather than bicycle or foot traffic. People work downtown and live in the suburbs. Longing for suburbia has led to urban sprawl, resulting in great distances between work and home. People spend large amounts of time and consume huge amounts of nonrenewable fossil fuels commuting to and from work over pavement that is simply too far, or too dangerous, to walk or to ride on a bicycle.

Urban lifestyles separate people from nature as well. Home from work or school, individuals 15 years and older spend approximately 2 hours and 30 minutes each day watching television, with the remainder of leisure time devoted to bits and pieces of activity that can be measured in minutes (U.S. Bureau of Labor Statistics, 2006). Meanwhile, younger children spend as much as six hours a day in front of one screen or another (Kaiser 
Foundation, 2005). Robinson and Godbey (1997) report that U.S. citizens spend $95 \%$ of the time indoors, leaving little time for outdoor activity.

The cumulative effect of city life on urbanites is a form of inertia, a sedentariness that permeates daily living and results in stresses and strains on people's minds and bodies. Obesity among all segments of the population is on the rise in the United States (National Alliance for Nutrition and Activity, 2003) as is stress (American Institute of Stress, 2008). Exacerbating the situation is an uneven distribution of wealth and uneven access to leisure opportunities within the cityscape that make some neighborhoods and some residents even more at risk of urban-related sicknesses (Giles-Corti \& Donovan, 2003; Gobster, 2001; Sasidharan, Willits, \& Godbey, 2005). According to Godbey (2009), the ultimate remedy for the collective affliction requires a comprehensive redesign of cities based on mixed use zoning and "smart growth" principles that facilitate going outside, being active, and connecting with nature. The monumentality of the challenge is staggering, but to give up on it would be to surrender the health of $85 \%$ of the citizenry. Consequently, it behooves park, recreation, and tourism professionals now more than ever to articulate what they can contribute to health promotion in the context of contemporary urban life.

\section{Health Benefits of Outdoor Recreation}

A growing body of knowledge demonstrates the significant health benefits derived from outdoor recreation. Studies linking increased physical activity and increased physical fitness with access to local parks and greenways are evident throughout the literature (Kaczynski \& Henderson, 2007; Kaczynski, Potwarka, \& Saelens, 2008; Kahn et al., 2002; Sallis, Prochaska, \& Taylor, 2000), as are studies linking well-placed and well-maintained local parks and greenways with healthy communities (Frumkin, 2003). Clearly, health promotion power in outdoor recreation is evidenced by the numerous physiological and psychological benefits associated with experiencing outdoor environments (Kaplan, 1995; Ulrich, 1981).

What the research suggests to date are strong positive correlations between outdoor recreation participation and beneficial health outcomes. People who participate in outdoor recreation are in disproportionately good health, and people in good health participate disproportionately more in outdoor recreation (Payne et al., 2005). The biggest health benefits accrue to people who make a habit of outdoor recreation participation, and the best opportunities to experience beneficial health outcomes from outdoor recreation participation are close to home in the form of municipal parks and recreation settings (Godbey, 2009).

While the circumstantial evidence documenting the health promotion power of outdoor recreation engagements is persuasive, drawing specific causal inferences about health outcomes from those engagements is problematic. This problem is due, in part, to methodological shortcomings that take participant self-reports at face value (Chase \& Godbey, 1983), rely on participants' faulty memories of past outdoor recreational involvement (Chase \& Harada, 1994), and treat outdoor recreation pursuits as if they were one activity when they are frequently made up of multiple activities. More important, the field's heavy reliance on survey research does not lend itself to causal inference. There is a glaring need for experimental research that probes causation, which has the potential to lead to strong causal inference.

Despite these methodological issues, Godbey (2009) concluded that ample evidence supports the assertion that recreating in the outdoors contributes to human health in broad and interrelated ways. Sallis, Prochaska, and Taylor (2000) reinforced this assertion by claiming that the association between physical activity and being outdoors is so strong that being outdoors is the best predictor of preschool children's physical activity. Yet there are numerous obstacles preventing the population in general and children in particular 
from enjoying nature. Unequal access to and information about local park and recreation opportunities are major barriers (Bixler \& Floyd, 1997; Floyd et al., 2008) as is parental concern for children's safety, a decline in unstructured free play time, poorly designed outdoor spaces, and the litigious nature of society (Louv, 2005). These obstacles must be overcome if adults and children alike are to be reacquainted with their natural heritage. The importance of removing constraints to outdoor recreation participation cannot be overemphasized. The health benefits of regular unstructured time outdoors for children are multifaceted, and outdoor play settings facilitate children's most powerful form of learning, that is, learning by doing. The outdoors may provide the best context for children to understand the workings of the larger world (Godbey, 2009).

Moreover, exercising the human body is critical to enhancing human health, and outdoor recreation provides what may be the best opportunity for people to move in an enjoyable and sustainable manner. Opportunities for exercise in work or household-related activities are intermittent as are opportunities specifically to improve health (e.g., fitness centers) (Godbey, 2009). The best hope for sustaining exercise may be when it is an inherent part of a pleasurable experience. Enhanced health then becomes a byproduct of doing something one finds joy in, something intrinsically motivating, and something that has staying power (Chow, 2007; Godbey, 2009). These characteristics may account for the unique contribution of recreation engagements to health promotion.

\section{Nature's Restorative Potential}

Researchers have also addressed whether health benefits differ between natural and built environments (Hartig \& Evans, 1993; Kweon et al., 2006; Ulrich, 1983). Their findings suggest that people not only prefer natural environments to built environments, but they also perceive that natural environments offer them greater potential for positive experiences (Wohlwill, 1983). The tendency to think of and respond to natural environments more positively may be because they allow people to recover from the stresses and strains of daily living (Hartig \& Evans, 1993; Hartig, Mang, \& Evans, 1991). Stress reduction, considered to be a major benefit of parks and open space since Olmsted and Vaux designed New York City's Central Park in the middle of the 19th century (Rybcznyski, 1999; Sax, 1980), may be the single most important therapeutic outcome that increasing contact with the natural world offers contemporary urban dwellers (Godbey, 2009).

The health benefits of an active outdoor lifestyle also extend from people to nature. When people get out of their houses and cars and set out on a bicycle or on foot, they reduce the demand for limited nonrenewable fossil fuels, thereby reducing air pollution and global warming. To the extent these activities are sustained over time, all will be able to enjoy cleaner air to breathe and cleaner water to drink. The health of the environment itself will likely improve as the collective load is lightened and the carbon footprint is reduced. A healthier environment will then be in better shape to give back health benefits of its own. Parks and greenways, for example, can mitigate air pollution (American Forests, 2002) and reduce increased temperatures (Center for Urban Horticulture, 2008). To realize these benefits, however, green spaces and accessible pathways must be designed into the cityscape in ways that improve both human health and the health of the underlying ecological system (Rails to Trails Conservancy, 2009; Takano, Nakamura, \& Watanabe, 2002).

The health-restoring properties of natural environments are even more far reaching. S. Kaplan's (1995) work on Attention Restoration Theory suggests that interactions with nature can reverse directed attention fatigue, an affliction common to the pressurized modern world. The effort involved in focusing attention on work-related tasks is exhausting, and S. Kaplan theorized that encounters with nature replenish fatigued directed attention capacity. 
Something appears to be inherently therapeutic about communing with nature (Bodin \& Hartig, 2003). Even children with Attention Deficit Disorder benefit from nature's healing properties (Faber Taylor, Kuo, \& Sullivan, 2001; Kuo \& Faber Taylor, 2004). Finally, small doses of nature in the midst of an urban setting yield micro-restorative experiences (Kaplan, 2001). In a landmark study of a hospital setting, Ulrich (1984) found that patients recovering from surgery who had a window overlooking a natural scene recovered more quickly than patients whose view overlooked a built environment. These and similar findings have spawned new efforts to design buildings, towns, and cities that weave more greenery into the fabric of urban landscapes (Beatley, 2000; Robert Wood Johnson Foundation, 2000).

\section{Ecological Model of Health Promotion}

In sum, like a pianist's glissando, the preventive power of active outdoor living sounds healthy notes emanating from the individual to the larger environment, while the therapeutic power of a healthier environment reverberates back to the individual by sounding healthy notes of its own. The resulting harmony reflects the striking of symbiotic keys. The individual, through a healthier lifestyle, reduces his or her carbon footprint on the larger world, while the larger world reciprocates with cleaner air, cleaner water, and an abundance of health restoring properties.

This symbiosis demonstrates that health is a dynamic relationship that can best be understood by conceiving it in broad ecological terms. Health, from an ecological perspective, is a measure of the wellness of the individual and the community considered together. The individual cannot be healthy independent of the condition of the larger community, and the larger community cannot be healthy independent of the condition of the individuals constituting it. Healthy individuals require healthy families, healthy families require healthy communities, healthy communities require healthy nations, healthy nations require a healthy planet, and so on. Health, at its core, is symbiotic in nature (Schwab, Dustin, \& Bricker, 2009).

This ecological approach to health promotion frames the interconnectedness and interdependence of the natural and physical attributes of the world into a more coherent and systematic way of thinking. It illustrates the harmonious potential that should define humankind's relationship with the larger world. As Figure 1 shows, there is a strong symbiotic relationship between ecosystem health and the health of the functional units that make up ecosystems, including humans. The model also recognizes the role humans play in affecting ecosystems as well as ecosystem effects on humans. The emphasis is on sustaining the health of the planet as a whole as well as its interdependent parts.

When evaluating the relationship between a healthy planet and sustaining healthy people, communities, and nations, the intricacy of this vast web of interrelationships becomes clear. Think of global climate change and its associated health-related reverberations all the way down to the level of individual life forms. At the same time, the model reflects how an environmentally friendlier code of human conduct has the potential to reverberate outward resulting in large scale environmental improvements. Individual human beings can deliver health benefits to the planet, while a healthier planet can reciprocate by:

- Filtering toxic substances from the air, water, and soil;

- Protecting against flooding, storm surges, and erosion;

- Breaking down wastes and recycling substances;

- Pollinating crops and wild plant species;

- Creating and maintaining soil fertility;

- Sequestering carbon that mitigates global climate change; 


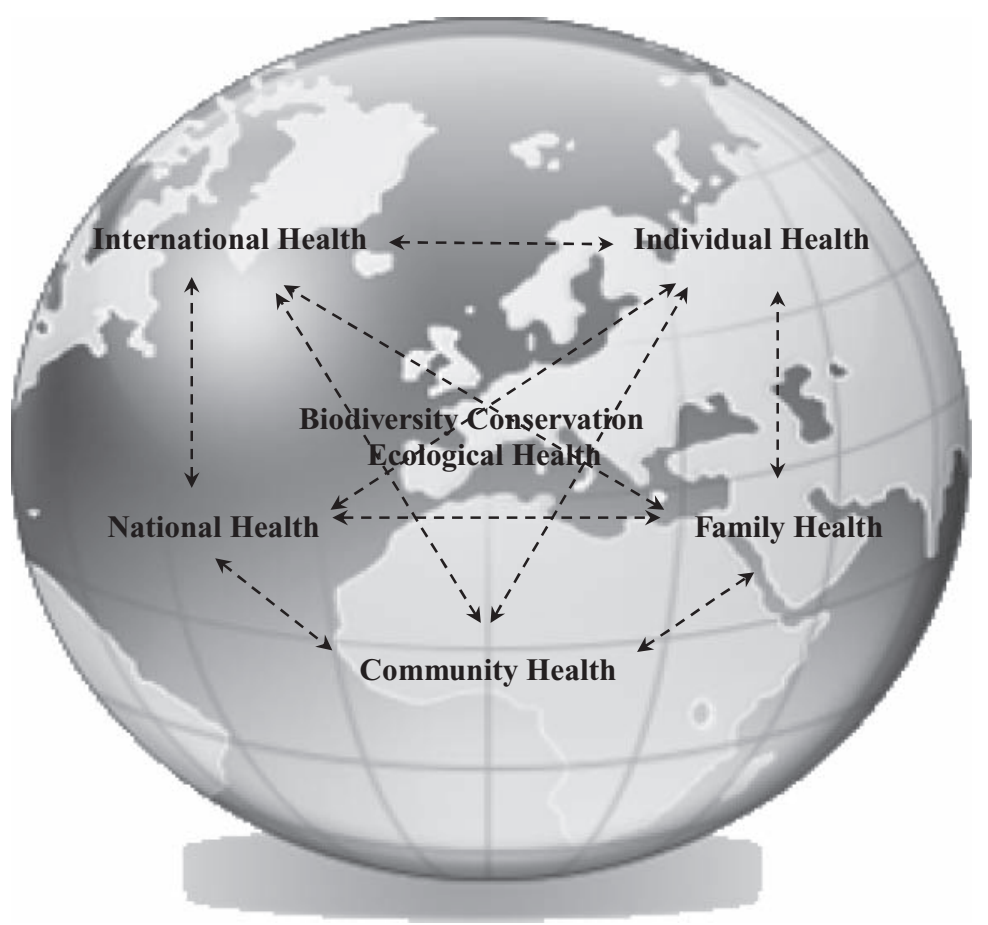

FIGURE 1 Ecological model of health promotion.

- Helping maintain the water cycle and stabilize local climates;

- Feeding, clothing, and sheltering us; and

- Giving us a host of other goods and services that support life, including human life on earth (Chivian, 2004, pp. 26-27).

These ecosystem "services" fill not only fundamental biological needs but also cultural needs for recreational, aesthetic, and spiritual well-being (Millennium Ecosystem Assessment, 2003).

Further, people depend on the planet for medicines that originate from diverse types of ecosystems. These ecosystems also help understand disease, support the food web upon which people depend, and reduce the risks of contracting infectious diseases (Chivian, 2004; Chivian \& Bernstein, 2004). Knowing all this, the planet is rarely placed front and center in thinking about how to conceptualize health in society. Humankind's dependence on a healthy planet is obscured by affluence in the Western industrialized world, while the world's poorest countries have no such economic buffer to shield them from their direct dependence on the health of the planet for their welfare (Chivian, 2004).

Conservation of biodiversity is the centerpiece for sustaining health in all of its manifestations (Chivian \& Bernstein, 2008). Threats to biodiversity and the consequences of its losses, including the obvious ecological consequences as well as the impact on aesthetic, ethical, sociological, and economical aspects of the world, reveal the reality of our dependence on a healthy planet. The significance of these relationships extends from the local to the global level, affecting the health not only of individual human beings but also of the earth as a whole. Put simply, humans depend on the health of other species and on the "healthy functioning of natural ecosystems" for their own personal health (Annan, 2008, p. ix). 
What an ecological model of health promotion demonstrates is that individual, familial, communal, national, international, and global health is highly intertwined and interdependent. Negative perturbations in any of the functional units may have untold negative rippling effects on the earth as a whole, thereby diminishing its ability to deliver ecosystem services of its own. The model also reflects the central role that humans play for better or worse in health promotion. The overarching lesson is that for the earth to deliver its products and nonmaterial benefits to humankind, its health must be looked after as well.

\section{Toward a More Comprehensive Health Promotion Strategy}

An ecological model of health promotion implies that the benefits of parks, recreation, and tourism inevitably will be measured by the degree to which they help sustain the health of all life. In this regard, encouraging and facilitating active outdoor living is an affordable proactive strategy for averting many of the chronic diseases plaguing a sedentary urban population. Preventing health problems is simply cheaper than paying for medical treatment after the fact. For this reason alone, parks, recreation, and tourism services should be embraced as part of a comprehensive health promotion strategy. If physical, mental, and emotional well-being can be improved by walking, hiking, biking, climbing, running rivers, skiing, snowboarding, snowshoeing, and a host of other outdoor pursuits (Pretty et al., 2005; Van den Berg, Hartig, \& Staats, 2007), then these activities should be considered integral to a common sense cure for what ails people, a cure made all the more palatable by mounting scientific evidence demonstrating their efficacy and cost effectiveness.

At the same time, getting back to nature can help restore the earth's health. This possibility requires careful consideration of the ways in which people act when recreating in the outdoors. Choosing recreational pastimes that reduce our carbon footprint and help restore nature's ability to deliver ecosystem services is essential to the reciprocity upon which health depends in its broadest sense. Focusing on human health alone runs the risk of ignoring the harm that can be done to the health of the planet by some forms of outdoor recreation. In the long run, this harm could diminish human health as well through a gradual erosion of the quality of outdoor recreation opportunities and environments (Dustin \& McAvoy, 1982). People cannot be healthy if the planet on which they live is unhealthy. The planet on which people live cannot be healthy if people persist in unhealthy human behaviors. Health is a harmonious ecological relationship that must be nurtured constantly.

\section{New Research Directions}

Appreciating health as a symbiotic relationship rooted in ecological understanding suggests a new orientation to studying the health promotion power of outdoor recreation engagements. On a macro level, interdisciplinary efforts are required to better understand the dynamics of the ecosystemic properties of health. As Godbey (2009) recommended, this approach would include research investigating synergistic potentials in community design and zoning, transportation, school policy, park and recreation policy, market-sector outdoor recreation opportunities, climate change, demographic change, and other contributors to, or inhibitors of, health promotion. Such an ecological orientation would be based on the realization that the major determinants of health have less to do with the health care system per se (Hancock, 1999) than with the environmental and social aspects of health (Chu \& Simpson, 1994). This is why park and recreation settings, especially those located close to home, may be ideally situated to foster health (Maller et al., 2006). 
Lack of contact with nature is a growing problem with effects only now beginning to be understood. Evidence suggests that the disconnect results in serious negative health consequences. Additional research is needed to better understand nature's health-restoring properties, the barriers to benefiting from those properties (especially for children), and how to break down those barriers. A particularly important subcontext to this line of inquiry is the decreasing amount of children's free play time in the outdoors. The costs and benefits of highly structured play for children need to be better understood as well as the ways in which children benefit from unstructured outdoor play. Laboratories abound for this research, including neighborhood vacant lots, school yards, local parks, and organized camps.

As outdoor recreation trends research has shown, participation patterns are highly skewed and outdoor recreation planners and policymakers must provide opportunities that are more appealing to ethnic minorities and women (Floyd, Crespo, \& Sallis, 2008; Shinew et al., 2006). Park and recreation professionals must better understand the interests of ethnic minorities and women as well as the constraints to their participation, and then set about accommodating those interests and removing those constraints. The impetus for this research is rooted in social justice in the provision of public park and recreation opportunities (Floyd \& Johnson, 2002) and in a concern for planning for a preferred future that serves the needs of all citizens.

A rapidly aging population should also be the focus of increased research attention. Current estimates indicate that one in five U.S. citizens is 65 years or older and this percentage will more than double by the middle of the century (U.S. Census Bureau, 2006). People are also living longer, and the number of citizens 85 years or older will triple by 2050 . Planning environmentally friendly and sustainable outdoor recreation opportunities for a much larger older population with declining physical abilities will require forethought and creativity on the part of outdoor recreation planners and policymakers, landscape architects, and other allied health professionals. Interdisciplinary research that informs this planning process should be a top priority.

Partnerships between parks and recreation and allied health agencies must be evaluated as well for their effectiveness in reducing social health care costs. There has been little evaluative research on these partnerships (Spangler \& Caldwell, 2007), even though parks and recreation is now widely recognized as a health promotion profession. Efforts by Driver (2009) and others to program specifically for health-related benefits is encouraging. Researchers are in the nascent stage of demonstrating the park and recreation profession's contributions to human and environmental health (Godbey et al., 2005). This research should be a primary focus framed by an ecological orientation to health promotion.

The role of tourism in fostering health, especially at the communal, national, and international levels, warrants heightened attention. The potential health benefits emanating from a maturing tourism industry dedicated to social and environmental responsibility and sustainability need to be better documented to illustrate the industry's contributions to health in its broadest contexts - sustainable economic development, enhanced cross-cultural understanding, friendship, and peace (Brandon, 1996; McAvoy, Dustin, \& Clements, 1991).

Finally, the costs as well as the benefits of outdoor recreation engagements must be factored into the health promotion equation (Dustin, McAvoy, \& Goodale, 1999). This focus is necessary to establish a sustainable foundation for enlightened service delivery. At its core, everything depends on the health of the planet. An ecological perspective makes this core clear. It illustrates the critical role of parks, recreation, and tourism in enhancing the quality of life for individuals, families, communities, nations, and the world at large. The park, recreation, and tourism profession, as much as any other profession is well-suited and well-positioned to help create a healthy sustainable future. By this same test, this profession 
must dedicate itself and its resources to the joyful promotion of health as a fundamental quest.

\section{Conclusion}

An ecological model of heath promotion is rooted in a worldview that sees humankind as part of nature. Western civilization has challenged this view from Descartes to the present day (Dustin, 1992), but advances in ecological understanding reaffirm humankind's physiological, psychological, and spiritual rootedness in the natural world (Rolston, 1996). The ongoing challenge is to embrace this ecological reality and reconnect with nature in ways that contribute to the individual and collective health of all living things. The challenge is particularly crucial to the healthy growth and development of children on whose behalf today's adult population bears the burden of responsibility. As Goodale avowed, " $[t]$ here is nothing more central to the evolution of human society and culture than the responsibility of each generation for the next" (Dustin, 1994, p. 31). With this responsibility in mind, it is time to acknowledge and advocate for the park, recreation, and tourism profession's centrality to the resolution of many health-related problems plaguing our sedentary and urbanized way of life.

\section{References}

Altman, I., \& Wohlwill, J. (Eds.). (1983). Human behavior \& environment: Advances in theory and research. New York: Plenum Press.

American Forests. (2002). Projected environmental benefits of community tree planting: A multi-site urban forest project in Atlanta. Washington, DC: American Forests. Retrieved February 2, 2009, from http://www.americanforests.org/downloads/rea/AF_Atlanta2.pdf

American Institute of Stress. (2008). America's no. 1 health problem. Retrieved March 5, 2009, from http://www.stress.org/about.htm

Annan, K. (2008). Prologue. In E. Chivian \& A. Bernstein (Eds.), Sustaining life: How human health depends on biodiversity (p. ix). New York: Oxford University Press.

Beatley, T. (2000). Green urbanism: Learning from European cities. Washington, DC: Island Press.

Bixler, R., \& Floyd, M. (1997). Nature is scary, disgusting and uncomfortable. Environment and Behavior, 29, 443-467.

Bodin, M., \& Hartig, T. (2003). Does the outdoor environment matter for psychological restoration gained through running? Psychology of Sport Exercise, 4(2), 142-153.

Brandon, K. (1996). Ecotourism and conservation: A review of key issues. Environmental Department Papers (No. 033). Washington, DC: The World Bank.

Center for Urban Horticulture, University of Washington. (2008). Retrieved March 15, 2009, from http://www.cfr.washington.edu/Research/fact_sheets/20-UrbEconBen.pdf

Chase D., \& Godbey, G. (1983). The accuracy of self-reported participation rates: A research note. Leisure Studies, 2, 123-126.

Chase, D., \& Harada, M. (1994). Response error in self-reported recreation participation. Journal of Leisure Research, 16(4), 322-329.

Chawla, L. (1988). Children's concern for the natural environment. Children's Environments Quarterly, 5(3), 13-20.

Chawla, L. (1998). Significant life experiences revisited: a review of research on sources of environmental sensitivity. Journal of Environmental Education, 29(3), 11-21.

Chivian, E. (2004). Beyond wildlife-health and conservation. In D. Roe (Ed.), The millennium development goals and conservation: Managing nature's wealth for society's health (pp. 2535). London: International Institute for Environment and Development.

Chivian, E., \& Bernstein, A. (2004). Guest editorial: Embedded in nature: Human health and biodiversity. Environmental Health Perspectives, 112(1), A12-A13. 
Chivian, E., \& Bernstein, A. (Eds.). (2008). Sustaining life: How human health depends on biodiversity. New York: Oxford University Press.

Chow, H. (2007). Physically active leisure among older adults-measurement, comparison and impact. Saarbrucken, Germany: VDM Verlag Publishers.

Chu, C., \& Simpson, R. (1994). Ecological public health: From vision to practice. Queensland, Australia: Institute of Applied Environmental Research, Griffith University, and Toronto, Canada: Centre for Health Promotion, University of Toronto.

Clements, R. (2004). An investigation of the state of outdoor play. Contemporary Issues in Early Childhood, 5(1), 68-80.

Driver, B. (Ed.). (2009). Managing to optimize the beneficial outcomes of recreation. State College, PA: Venture Publishing.

Dustin, D. (1992). The dance of the dispossessed: On patriarchy, feminism, and the practice of leisure science. Journal of Leisure Research, 24(4), 324-332.

Dustin, D. (1994). The weight of the world: Why camp is ever more important. Camping Magazine, 66(4), 26-31.

Dustin, D., \& McAvoy, L. (1982). The decline and fall of quality recreation opportunities and environments. Environmental Ethics, 4(1), 49-57.

Dustin, D., McAvoy, L., \& Goodale, T. (1999). The benefits equation. Parks \& Recreation, 34(1), 32-37.

Faber Taylor, A., Kuo, F., \& Sullivan, W. (2001). Coping with ADD: The surprising connection to green play settings. Environment and Behavior, 33(1), 54-77.

Faber Taylor, A., Kuo, F., \& Sullivan, W. (2002). Views of nature and self-discipline: Evidence from inner city children. Journal of Environmental Psychology, 22, 49-63.

Faber Taylor, A., \& Kuo, F. (2006). Is contact with nature important for healthy child development? State of the evidence. In C. Spencer \& M. Blades (Eds.), Children and their environments: Learning, using and designing spaces (pp. 124-158). Cambridge, UK: Cambridge University Press.

Floyd, M., Crespo, C., \& Sallis, J. (2008). Active living in diverse and disadvantaged communities: Stimulating dialogue and policy solutions. American Journal of Preventive Medicine, 34, 271274.

Floyd, M., \& Johnson, C. (2002). Coming to terms with environmental justice in outdoor recreation: A conceptual discussion with research implications. Leisure Sciences, 24, 59-77.

Floyd, M., Spengler, J., Maddock, J., Gobster, P., \& Suau, L. (2008). Park-based physical activity in diverse communities of two U.S. cities: An observational study. American Journal of Preventive Medicine, 34, 299-305.

Frumkin, H. (2003). Healthy places: Exploring the evidence. American Journal of Public Health, 93(9), 1451-1456.

Giles-Corti, B., \& Donovan, R. (2003). Relative influences of individual, social, environmental, and physical environmental correlates of walking. American Journal of Public Health, 93, 15831589.

Gobster, P. (2001). Neighborhood-open space relationships in metropolitan planning: A look across four scales of concern. Local Environment, 6, 199-212.

Godbey, G. (2009). Outdoor recreation, health, and wellness: Understanding and enhancing the relation. Washington, DC: Resources for the Future.

Godbey, G., Caldwell, L., Floyd, M., \& Payne, L. (2005). Contributions of leisure studies and recreation and park management research to the active living agenda. American Journal of Preventive Medicine, 28(2), 150-158.

Hancock, T. (1999). Healthy and sustainable communities-creating community capital. In 4th European IUHPE Conference on Effectiveness and Quality of Health Promotion. IUHPE, May 16-19, Tallinn, Estonia.

Hartig, T., \& Evans, G. (1993). Psychological foundations of nature experience. In T. Garling \& R. Golledge (Eds.), Behavior and environment: Psychological and geographical approaches (pp. 427-457). Bridgewater, NJ: Elsevier Science.

Hartig, T., Mang, M., \& Evans, G. (1991). Restorative effects of natural environment experiences. Environment and Behavior, 23(1), 3-26. 
Kaczynski, A., \& Henderson, K. (2007). Environmental correlates of physical activity: A review of evidence about parks and recreation. Leisure Sciences, 29(4), 315-354.

Kaczynski, A., Potwarka, L., \& Saelens, B. (2008). Association of park size, distance, and features with physical activity in neighborhood parks. American Journal of Public Health, 98(8), 14511456.

Kahn, E., Ramsey, L., Brownson, R., Heath, G., Howze, E., Powell, K., Stone, E. J., Rajab, M. W., \& Corso, P. (2002). The effectiveness of interventions to increase physical activity. American Journal of Preventive Medicine, 22(4S), 87-88.

Kaiser Foundation. (2005). Generation M: Media in the lives of 8-18 year olds. Retrieved March 2, 2009, from www.kff.org/entmedia/7250.cfm

Kaplan, R. (2001). The nature of the view from home: Psychological benefits. Environment and Behavior, 33(4), 507-542.

Kaplan, R., \& Kaplan, S. (1989). The experience of nature: A psychological perspective. Cambridge, UK: Cambridge University Press.

Kaplan, S. (1995). The restorative benefits of nature: Toward an integrative framework. Journal of Environmental Psychology, 15, 169-182.

Kellert, S. (2005). Building for life: Designing and understanding the human-nature connection. Washington, DC: Island Press.

Kuo, F., \& Faber Taylor, A. (2004). A potential natural treatment for attention-deficit/hyperactivity disorder: Evidence from a national study. American Journal of Public Health, 94(9), 1580-1586.

Kweon, B., Ellis, C., Lee, S., \& Rogers, G. (2006). Large-scale environmental knowledge: Investigating the relationship between self-reported and objectively measured physical environments. Environment and Behavior, 38(1), 72-91.

Louv, R. (2005). Last child in the woods: Saving our children from nature deficit disorder. Chapel Hill, NC: Algonquin Books.

Maller, C., Townsend, M., Pryor, A., Brown, P., \& St. Leger, L. (2006). Healthy nature healthy people: 'Contact with nature' as an upstream health promotion intervention for populations. Health Promotion International, 21, 45-54.

McAvoy, L., Dustin, D., \& Clements, C. (1991). Tourism's role in building a better world. In J. Zeiger \& L. Caneday (Eds.), Tourism and leisure: Dynamics and diversity (pp. 93-102). Alexandria, VA: NRPA Publications.

Millennium Ecosystem Assessment. (2003). Ecosystems and human well-being: A framework for assessment. Washington, DC: Island Press.

National Alliance for Nutrition and Activity. (2003). Obesity and other diet and inactivity-related diseases: National impact, costs, and solutions. Retrieved March 17, 2009, from www.cspinet. org/nutritionpolicy/briefingbookfy04.ppt

Outdoor Industry Foundation. (2008). Outdoor Recreation Participation Study for 2008. Retrieved February 10, 2009, from http://www.outdoorfoundation.org/research.participation.2008.html

Payne, L., Orsega-Smith, E., Roy, M., \& Godbey, G. (2005). Local park use and personal health among older adults: An exploratory study. Journal of Park and Recreation Administration, 23(2), 1-20.

Pergams, O., \& Zaradic, P. (2006). Is love of nature in the United States becoming love of electronic media? 16-year downtrend in national park visits explained by watching movies, playing video games, Internet use, and oil prices. Journal of Environmental Management, 80(4), 287293.

Pretty, J., Peacock, J., Sellens, M., \& Griffin, M. (2005). The mental and physical health outcomes of green exercise. International Journal of Environmental Health Research, 15(5), 319337.

Proshansky, H., Ittelson, W., \& Rivlin, L. (Eds.). (1970). Environmental psychology: Man and his physical setting. New York: Holt, Rinehart and Winston.

Rails to Trails Conservancy. (2009). Retrieved May 3, 2009, from http://www.railstotrails.org/ whatwedo/railtrailinfo/benefits.html

Robert Wood Johnson Foundation. (2000). Healthy places, healthy people: Promoting public health \& physical activity through community design. Princeton, NJ: Robert Wood Johnson.

Robinson, J., \& Godbey, G. (1997). Time for life: The surprising ways Americans use their time. University Park, PA: The Pennsylvania State University Press. 
Rolston, H. (1996). Nature, spirit, and landscape management. In B. Driver, D. Dustin, T. Baltic, G. Elsner, \& G. Peterson (Eds.), Nature and the human spirit: Toward an expanded land management ethic (pp. 17-24). State College, PA: Venture Publishing, Inc.

Rybczynski, W. (1999). A clearing in the distance: Frederick Law Olmsted and America in the nineteenth century. New York: Scribner.

Sallis, J., Prochaska, J., \& Taylor, W. (2000). A review of correlates of physical activity of children and adolescents. Medicine and Science in Sports and Exercise, 32, 963-975.

Sasidharan, V., Willits, F., \& Godbey, G. (2005). Cultural differences in urban recreation patterns: An examination of park usage and activity participation across six population subgroups. Managing Leisure, 10, 19-38.

Sax, J. (1980). Mountains without handrails: Reflections on the national parks. Ann Arbor: The University of Michigan Press.

Schwab, K., Dustin, D., \& Bricker, K. (2009). Parks, recreation and tourism's contributions to Utah's health: An ecologic perspective. Leisure Insights, 29(1), 12-14.

Shinew, K., Stodolska, M., Floyd, M., Hibbler, D., Allison, M., Johnson, C. (2006). Race and ethnicity in leisure behavior: Where have we been and where do we need to go. Leisure Sciences, 28, 403-408.

Spangler, K., \& Caldwell, L. (2007). The implications of public policy related to parks, recreation, and public health: A focus on physical activity. Journal of Physical Activity and Health, 4(1), 64-71.

Takano, T., Nakamura, K., \& Watanabe, T. (2002). Urban residential environments and senior citizens' longevity in megacity areas: The importance of walkable green spaces. Journal of Epidemiology and Community Health, 56(12), 913-918.

Turner, W., Nakamura, T., \& Dinetti, M. (2004). Global urbanization and the separation of humans from nature. BioScience, 54(6), 585-590.

Ulrich, R. (1981). Natural versus urban scenes: Some psychophysiological effects. Environment and Behavior, 13(5), 523-556.

Ulrich, R. (1983). Aesthetic and affective response to natural environment. In I. Altman \& J. Wohlwill (Eds.), Human behavior and environment: Advances in theory and research 6 (pp. 85-125). New York: Plenum.

Ulrich, R. (1984). View through a window may influence recovery from surgery. Science, 224, 420-421.

U.S. Bureau of Labor Statistics. (2006). Retrieved February 10, 2009, from http://www.bls.gov/tus/ datafiles_2006.htm

U.S. Census Bureau. (2006). Retrieved January 25, 2009, from http://www.census.gov/ population/www/socdemo/age/age_2006.html

U.S. Department of Health and Human Services. (2008). Overweight and obesity: Health consequences. Atlanta, GA: U.S. Department of Health and Human Services, Centers for Disease Control and Prevention. Retrieved December 13, 2008, from http://www.cdc.gov/nccdphp/dnpa/ obesity/consequences.htm

Van den Berg, A., Hartig, T., \& Staats, H. (2007). Preference for nature in urbanized societies: Stress, restoration, and the pursuit of sustainability. Journal of Social Issues, 63(1), 79-96.

Wilson, E. (1993). Biophilia and the conservation ethic. In S. Kellert \& E. Wilson (Eds.), The biophilia hypothesis (pp. 31-41). Washington, DC: Island Press.

Wohlwill, J. (1983). The concept of nature: A psychologist's view. In I. Altman \& J. Wohlwill (Eds.), Human behavior and environment: Advances in theory and research 6 (pp. 5-37). New York: Plenum. 